\title{
MANUSCRITOS Y TRADICIÓN TEXTUAL Desde los orígenes hasta c. 1350
}

\author{
CARlos Alvar
}

Universidad de Alcalá

Es un hábito frecuente ya que las ediciones de textos serias vayan acompañadas por un estudio detallado de su tradición manuscrita, a pesar de la gran pobreza de testimonios que acosa a nuestra literatura medieval. Poco a poco, las historias de la literatura también van dejando un hueco a diversas consideraciones relacionadas con la tradición de los textos, que en obras como el $\mathrm{Li}$ bro de buen amor o El conde Lucanor adquieren especial importancia, pues afectan de forma directa a la estructura y contenido de las mismas.

Los estudiosos de la literatura española de la Edad Media disponemos, además, de un excelente repertorio de manuscritos - la Bibliography of Old Spanish Texts- llevado a cabo por Ch. Faulhaber y A. Gómez Moreno, con la colaboración de otros ${ }^{1}$, y cuya cuarta edición ya se puede manejar; disponemos también de una utilísima recopilación, $\mathrm{ADMYTE}^{2}$, e incluso podemos contar con una obra sobre los textos perdidos ${ }^{3}$. Y a este panorama habría que añadir el ingente catálogo de la poesía cancioneril de B. Dutton ${ }^{4}$, y algunos trabajos más concretos, sobre determinadas obras ${ }^{5}$; natu-

\footnotetext{
${ }^{1}$ Bibliography of Old Spanish Texts, 3rd. ed., Compiled by Ch. B. Faulhaber, A. Gómez Moreno, D. Mackenzie, J. J. Nitti, B. Dutton (with the assistance of J. Lentz), Madison, Hispanic Seminary of Medieval Studies, 1984.

${ }^{2}$ AA.VV., Archivo digital de manuscritos y textos españoles (ADMYTE 1). Madrid, Micronet-Ministerio de Cultura-Fundación V Centenario, 1992; id., vol. 0, 1994.

3 A. D. Deyermond, La literatura perdida de la Edad Media castellana. Catálogo y estudio. I. Épica y romances, Salamanca, Universidad, 1995.

${ }^{4}$ B. Dutton, El cancionero del siglo XV (c. 1360-1520), 7 vols., Salamanca, Biblioteca española del siglo XV-Universidad de Salamanca, 1991.

${ }^{5}$ Así, C. García Turza, La tradición manuscrita de Berceo con un estudio filológico particular del ms. 1533 de la BNM, Logroño, Instituto de Estudios Riojanos, 1979; I. Uría, «Sobre la transmisión manuscrita de las obras de Berceo», Incipit, 1, 1981, págs. 13-23, o A. Blecua, La transmisión textual del Conde Lucanor, Bellaterra, Universidad Autónoma de Barcelona, 1980.
} 
ralmente, en esta enumeración somera no puede faltar la referencia a una publicación periódica, Incipit, que desde sus orígenes se ha ocupado con especial atención de las cuestiones relativas a ecdótica y transmisión textual ${ }^{6}$.

Las herramientas de las que disponemos son abundantes, aunque aún no tenemos todos los útiles necesarios, y la disparidad de criterios en el análisis de la tradición textual se hace evidente debido a la dispersión de los trabajos. Por todo ello, hemos considerado necesario emprender la sistematización de los materiales existentes, reuniendo en el presente repertorio una especie de vademecum, una breve guía para quienes deseen adentrarse un poco más en el intrincado bosque de las arborescencias ecdóticas.

Este trabajo tiene muchas limitaciones: la primera, cronológica, pues sólo llega hasta mediados del siglo XIV. Otra limitación es de índole formal, pues no se ha dado cabida a testimonios aljamiados, que plantean problemas específicos en la transmisión textual: del Poema de Yúçuf hay dos manuscritos, ambos fragmentarios (Real Academia de la Historia, T-12 y BNM, Res. 247); de las Coplas de Yóçef se conservan también dos fragmentos (Bibliothèque Nationale de Paris y Cambridge University, Add. 3.355, ambos aljamiados en árabe) y hay noticias de otro fragmento aljamiado en hebreo (Biblioteca Vaticana); la Alhotba procede de un manuscrito único del siglo XIV (Escorial, árabe 1880) en el que se encuentra también un poema en Loor de Mahoma (Almahda) ${ }^{7}$. A este grupito de obras hay que añadir, naturalmente, las jarchas, conservadas en el 'Uddat de 'Ali ibn Busrà al-Igranatí (manuscrito único perteneciente a G.S. Colin), en el Gays al-tawsih de Lisan al-Din ibn al-Hatib (Biblioteca de la mezquita al-Zaytuniya de Túnez; Biblioteca particular de Muhammad al-Nifar y Biblioteca particular de H. H. Abdul-Wahab; los dos últimos manuscritos parecen estar relacionados entre sí) y en el Tawsi' al-tawsih de Salah al-Din al-Safadí (ms. único, en El Escorial); las jarchas procedentes de moaxajas hebreas se encontraban casi todas en la Guenizá de Fostat (El Cairo), aunque se dispersaron por varias bibliotecas (Adler, New York, mss. 2158, 2818, 2193, 3419, 2385; Cambridge T.-S. Loan 63, H 15, 8 K 14, 108, 96, n.s. 114, n.s. 111; British Library, ms. 5557 D, Or. 5557 P; Berlín 103, 186; Oxford ms. 1971, 1970, 2853, Hebr. e. 100, 1972; Frankfurt 159; Jerusalén, ms. Schocken 37...) ${ }^{8}$.

\footnotetext{
${ }^{6}$ Incipit, 1, 1981, pág. 1.

7 Aljamía. Boletín de Información Bibliográfica, Oviedo, Universidad, desde 1989. A. Galmés de Fuentes, «La literatura española aljamiado-morisca», en GRLMA, IX/1, fasc. 4, Heidelberg, Carl Winter, 1985, págs. 117-132.

${ }^{8} \mathrm{M}^{\mathrm{a}}{ }^{\mathrm{J}}$. Rubiera Mata, Bibliografia de la literatura hispano-árabe, Alicante, Universidad, 1988, nn. 66-274; R. Hitchcock, The Kharjas: a critical bibliography, Londres, Grant \& Cutler, 1977; J. M. Solá-Solé, Corpus de poesía mozárabe, Barcelona, Ediciones Hispam, 1973, págs. 51-52.
} 
El material aquí reunido, y que se refiere a medio centenar de obras, se presenta ordenado según el género al que pertenecen, de acuerdo con un criterio propio de la Historia de la Literatura, y con el que hay una indudable familiarización. El lector curioso encontrará en cada epígrafe la relación y localización de los manuscritos que han conservado la obra, las ediciones más significativas del texto en cuestión y una bibliografía específica (repertorios bibliográficos, estudios codicológicos, noticias de nuevos manuscritos). No se ha planteado, pues, recoger de forma exhaustiva todos los estudios o trabajos sobre cada uno de los textos: se ha llevado a cabo una selección estricta para facilitar la consulta a quienes estén interesados en ampliar algunos datos.

Finalmente, parece ocioso advertir que es éste un trabajo provisional, que intenta llenar una laguna en nuestra medievalística: toda rectificación, corrección y adición serán bienvenidas.

\section{1. ÉPICA}

\subsection{Poema de Mío Cid}

El Poema de Mío Cid se conserva en un manuscrito copiado en el siglo XIV, al que le faltan desde antiguo tres hojas, una de las cuales afecta al comienzo del texto.

Los datos más remotos que poseemos del manuscrito del Poema de Mío Cid se sitúan en 1596; en el mes de octubre de ese año, Juan Ruiz de Ulibarri y Leyba fechó una copia que había sacado del texto que se custodiaba en el concejo de Vivar (cerca de Burgos), lugar de nacimiento del Cid: tanto el original copiado, como la copia se conservan en la Biblioteca Nacional de Madrid. En 1601, fray Prudencio de Sandoval vio en Vivar un texto que comenzaba: «De los sos ojos tan fuertemente lorando». Es evidente que la mutilación inicial del Poema es antigua.

Los únicos datos seguros que poseemos del Poema de Mio Cid son los que se desprenden de la copia conservada, que en época temprana se encontraba en el lugar de origen del héroe. Sin embargo, nada permite considerar que el texto fue compuesto en Vivar; más bien habría que pensar que se trata de la copia de un poema anterior: el texto más moderno sería el resultado de un encargo del concejo burgalés, que de este modo pretendería mantener siempre vivo el recuerdo de Ruy Díaz. Tal idea se sustenta en el hecho de que el manuscrito hoy conservado está copiado sobre pergamino basto, mal preparado: la utilización de este material en una época en que ya se había difundido el empleo del papel sólo puede deberse al interés por 
la conservación del Poema; sin embargo, la baja calidad del pergamino y su rudimentaria preparación hacen pensar que fue copiado en un lugar que carecía de los recursos suficientes para realizar un trabajo más esmerado y más de acuerdo con la finalidad a que se destinaba: por tanto, no debió ser copiado en la corte, ni en ningún monasterio especializado en este tipo de labores.

Actualmente el manuscrito se encuentra en la Biblioteca Nacional de Madrid (vitr. 7/17).

Ediciones: Excelente edición facsímil con estudio paleográfico y codicológico en H. Escolar Sobrino, Poema de Mio Cid, 2 vols., Burgos, Diputación Provincial, 1982. R. Menéndez Pidal, Cantar de mio Cid. Texto, gramática y vocabulario, 3 vols., 5. ${ }^{\mathrm{a}}$ ed., Madrid, Espasa-Calpe, 1977 [1. ${ }^{\mathrm{a}}$ ed. 1908-11]. I. Michael, Poema de Mio Cid, Madrid, Castalia, 1976. C. Smith, Poema de Mio Cid. Madrid, Cátedra, 1976. J. Horrent, Cantar de Mio CidChanson de Mon Cid, 2 vols., Gante, Éditions Scientifiques E. Story-Scientia, 1982. M. ${ }^{a}$ E. Lacarra, Poema de Mio Cid, Madrid, Taurus, 1983. P. M. Cátedra y B. Morros, Poema de Mio Cid, Barcelona, Planeta 1985. A. Montaner, Cantar de Mio Cid, Barcelona, Crítica, 1993.

Bibliografia: M. Magnotta, Historia y bibliografia de la crítica sobre el Poema de Mio Cid, Chapel Hill, University of North Carolina Press, 1976. F. López Estrada, Panorama critico sobre el Poema del Cid, Madrid, Castalia, 1982. J. L.Suárez García, «Hacia una bibliografía del Poema de Mio Cid (1981-1988)», C, 19, 1990, págs. 67-82. C. Alvar, "Tipología de la tradición de los cantares de gesta», en Actes du XIè Congrès International de la Société Rencesvals, 2 vols., Barcelona, Boletín de la Real Academia de Buenas Letras, 1990, págs. 395-423.

\subsection{Mocedades de Rodrigo}

Las Mocedades de Rodrigo ocupan el final de un manuscrito en papel, que en su mayor parte está dedicado a la Crónica de Castilla (también denominada Crónica del Campeador).

El texto presenta, por lo menos, diez lagunas y abundantes rasgos de una transmisión defectuosa y muy deturpada.

La copia debió ser realizada en la diócesis de Palencia o en algún lugar dependiente de ella, a juzgar por el interés con que trata varios asuntos relacionados con la Iglesia palentina, como el descubrimiento de la tumba de San Antolín, o la fundación de la diócesis. Palencia, que había tenido momentos de florecimiento en el siglo XIII, padeció una importante crisis a lo largo del siglo XIV, que acabó enfrentando al poder laico y al eclesiástico, 
hasta el punto de que en el año 1356 se prohibieron los servicios religiosos en la ciudad. En este contexto, se copia un poema anterior, reelaborándolo a favor de los intereses episcopales, y haciendo del protagonista -el famoso Cid - el protector laico de la Iglesia, frente a la nobleza local.

Se conserva en un manuscrito tardío de la Biblioteca Nacional de París (ms. espagnol, 12), de finales del siglo XIV.

Ediciones: R. Menéndez Pidal, Reliquias de la Poesía Épica Española. 2. ${ }^{a}$ edic., Madrid, Gredos, 1980. C. Alvar y M. Alvar, Épica Medieval Española, Madrid, Cátedra, 1991.

Bibliografía: C. Alvar, "Tipología de la tradición de los cantares de gesta», en Actes du XIè Congrès International de la Société Rencesvals. 2 vols., Barcelona, Boletín de la Real Academia de Buenas Letras, 1990, págs. 395-423.

\subsection{Roncesvalles}

Los únicos cien versos conservados de este cantar de gesta fueron copiados hacia 1310 (como el Poema de Mio Cid) y constituyen dos folios sueltos que aparecieron entre las hojas de un censo o registro de vecinos de Navarra, el Libro de fuegos de todo el Reyno, y se custodia actualmente en el Archivo Provincial de Pamplona. El pergamino presenta costuras que indican que en tiempos pretéritos fue utilizado como carpeta o bolsa: el deterioro que ha sufrido el texto debido al roce ha sido grave y las posibilidades de recuperar el resto del cantar son prácticamente nulas.

El texto original copiado en el pergamino pamplonés debió ser redactado a finales del siglo XIII, según Jules Horrent, aunque R. Menéndez Pidal pensaba en una antigüedad mayor que situaría el poema en el primer tercio del mismo siglo. Este texto fue copiado en Navarra y presenta los rasgos propios de la tradición gráfica de la región aunque los dialectalismos navarro-aragoneses son muy escasos en los cien versos conservados.

Ediciones: R. Menéndez Pidal, «Roncesvalles. Un nuevo cantar de gesta español del siglo XIII», RFE, 4, 1917, págs. 105-204. J. Horrent, Roncesvalles: Étude sur le fragment de cantar de gesta conservé à l'Archivo de Navarra (Pampelune), Paris, Société d'Éditions «Les Belles Lettres» (Bibliothèque de la Faculté de Philosophie et Lettres de l'Université de Liège, fasc. CXXII), 1951. M. de Riquer, Chanson de Roland-Cantar de Roldán y el Roncesvalles navarro, Barcelona, El Festín de Esopo, 1983. C. Alvar y M. Alvar, Épica Medieval Española, Madrid, Cátedra, 1991. I. Michael, 
"Orígenes de la epopeya en España: Reflexiones sobre las últimas teorías», Actas del II Congreso de la Asociación Hispánica de Literatura Medieval. Edic. a cargo de P. Gracia y J. M. Lucía Megías. 2 vols., Alcalá de Henares, Universidad, 1992; vol. I, págs. 71-88.

Bibliografia: C. Alvar, "Tipología de la tradición de los cantares de gesta», en Actes du XIè Congrès International de la Société Rencesvals. 2 vols., Barcelona, Boletín de la Real Academia de Buenas Letras de Barcelona, 1990, págs. 395-423.

\section{Poesía del Siglo XIII-1}

\subsection{Debate del alma y el cuerpo}

El Debate del alma y el cuerpo castellano se conserva en un folio (Archivo Histórico Nacional, Clero, carp. 279, n. 22) procedente del monasterio de Oña, al dorso de un documento escrito en el año 1201. El fragmento es copia de un original anterior, tal vez de finales del siglo XII.

Ediciones: R. Menéndez Pidal, «Disputa del alma y el cuerpo y Auto de los Reyes Magos», en Obras Completas, XII, Madrid, Espasa-Calpe, 1976, págs. 161-177. F. Gómez Redondo, Poesía española. 1. Edad Media, Barcelona, Crítica, 1996.

\subsection{Razón de amor con los denuestos del agua y el vino}

Se conserva el texto - que se suele fechar en el segundo tercio del siglo XIII- en un manuscrito único (Ms. lat. 3576 de la Biblioteca Nacional de París) que contiene varias homilías latinas y un breve manual de confesión en prosa castellana, conocido habitualmente como Los Diez Mandamientos.

Ediciones: R. Menéndez Pidal, «Razón de Amor con los Denuestos del agua y el vino», en Obras Completas, XII, Madrid, Espasa-Calpe, 1905 (1976), págs. 105-117. M. Di Pinto, Due contrasti d'amore nella Spagna medievale, Pisa. 1959, G. H. London, «The Razón de Amor and the Denuestos del agua y el vino. New Readings and Interpretations», RPh, 19, 1965-1966, 28-47. M. Barra Jover, «Razón de Amor: Texto crítico y composición», RLM, 1, 1989, págs. 123-153. E. Franchini, El manuscrito, la lengua y el ser literario de la Razón de Amor, Madrid, CSIC, 1993. F. Gómez Redondo, Poesía española. 1. Edad Media, Barcelona, Crítica, 1996. 


\subsection{Elena y María}

Se conserva - como los casos anteriores - en un manuscrito único (Biblioteca de los Duques de Alba), de reducido tamaño $(65$ x $55 \mathrm{~mm})$, escrito a principios del siglo XIV, copia de un texto anterior que presentaba ya alteraciones en el orden de sus folios, lo que indicaría que era - a su vezcopia de un texto más antiguo aún.

Ediciones: R. Menéndez Pidal, «Elena y María (Disputa del clérigo y el caballero). Poesía leonesa inédita del siglo XIII», RFE, 1, 1914, págs. 52-96. M. Di Pinto, Due contrasti d'amore nella Spagna, Pisa, 1959. F. Gómez Redondo, Poesía española. 1. Edad Media, Barcelona, Crítica, 1996.

\subsection{Poemas de asunto religioso}

Un manuscrito único del siglo XIV (Biblioteca del Monasterio de El Escorial, K.III.4) contiene, junto al Libro de Apolonio, otros dos textos que difieren de éste por el carácter menos cuidado de su métrica y por no utilizar la cuaderna vía, sino el verso octosílabo, igual que ocurría en los poemas de debates que adaptaban obras francesas. Se trata de la Vida de Santa María Egipcíaca y del Libro de la infancia y muerte de Jesús, dos textos hagiográficos, ajenos en gran medida a la tradición hispánica, y que fueron copiados por un escriba que dejó en la lengua de los dos textos claros testimonios de su origen aragonés.

\subsubsection{Vida de Santa María Egipciaca}

Ediciones: M. ${ }^{a}$ S. Andrés Castellanos, La Vida de Santa María Egipcíaca, Madrid, Anejos del Boletín de la Real Academia Española (Anejo XI), 1964. M. Alvar, Poemas hagiográficos de carácter juglaresco, Madrid, Ediciones Alcalá, 1967. M. Alvar, Vida de Santa María Egipcíaca, 2 vols., Madrid, Consejo Superior de Investigaciones Científicas, 1970-2. M. Schiavone de Cruz Sáenz, The Life of Saint Mary of Egypt: An Study of the Medieval French and Spanish Verse Redactions, Barcelona, Puvill, 1979. F. Gómez Redondo, Poesía española. 1. Edad Media, Barcelona, Crítica, 1996.

\subsubsection{Libro de la infancia y muerte de Jesús}

Ediciones: M. Alvar, Libro de la Infancia y Muerte de Jesús (Libre dels Tres Reys d'Orient), Madrid, CSIC, 1965. M. Alvar, Poemas hagiográficos de carácter juglaresco, Madrid, Ediciones Alcalá, 1967.

Bibliografia: M. Alvar Ezquerra, «Concordancias e índices léxicos del Libro de Infancia y Muerte de Jesús», Archivo de Filología Aragonesa, 26-27, págs. 421-60. 


\subsection{El planto Ay, Iherusalem}

Los 110 versos de que consta se conservan en un manuscrito único (Archivo Histórico Nacional, Madrid, Diversos, miscelánea, cajón 12) de finales del siglo XIV o principios del XV, que debe ser copia de otro de mediados del siglo XIII.

Ediciones: E. Asensio, "jAy Iherusalem! Planto narrativo del siglo XIII», NRFH, 14, 1960, págs. 251-270. M. C. Pescador del Hoyo, «Tres nuevos poemas medievales», NRFH, 14, 1960, págs. 242-250. F. Gómez Redondo, Poesía española. 1. Edad Media, Barcelona, Crítica, 1996.

\subsection{La Representación de los Reyes Magos}

Su conservación ha sido accidental, pues se copió a finales del siglo XII o comienzos del siglo XIII en los folios en blanco de un códice de la Catedral de Toledo (Biblioteca Nacional, Madrid, Vitr. 5-9). El poco cuidado que puso el copista, o el desinterés por el texto que copiaba, se aprecia no sólo en el aprovechamiento de los folios en blanco, sino también en el hecho de que no se respetaran los versos y que no se indicara cuándo empezaba a hablar cada uno de los personajes.

Ediciones: A. M. ${ }^{a}$ Álvarez-Pellitero, Teatro medieval castellano, Madrid, Espasa-Calpe (Austral, 157), 1990. R. E. Surtz, Teatro castellano de la Edad Media, Madrid, Taurus, 1992.

Bibliografía: C. J. Stratman, Bibliography of Medieval Drama, 2nd. ed. New York, 1972.

\section{Poesía del siglo XiII-2. El Mester de Clerecía}

\subsection{Gonzalo de Berceo}

No se han conservado más que algunos fragmentos de manuscritos medievales de las obras de Berceo; el conjunto de su producción poética nos ha llegado - fundamentalmente - a través de dos copias que se hicieron en el siglo XVIII sobre los originales del siglo XIII.

El más antiguo de los códices medievales, hoy perdido, se designa con la inicial $* \mathrm{Q}$, pues era un manuscrito in quarto, compuesto hacia 1260 . Entre 1325 y 1330 se copió el contenido de este códice en otro, tamaño in fo- 
lio (F), del que se conservan dos fragmentos en la Real Academia de la Lengua en Madrid (mss. 4 y 4b) y otro en una biblioteca particular de Santo Domingo de la Calzada.

En el siglo XVIII se copió ${ }^{*} \mathrm{Q}$, completando las lagunas mediante $\mathrm{F}$; este $\mathrm{ms}$. se conoce con el nombre de Ibarreta - de donde toma la sigla Iy se conserva en la biblioteca del Monasterio de Silos (ms. 93). Se incluyen todas las obras menos la Vida de Santo Domingo de Silos, que por el interés que tenía para el monasterio había sido objeto de una atención mayor, $\mathrm{y}$ que se había desgajado ya de $\mathrm{F}$ en esa época (y quizás en el siglo XVII).

Algo más tarde, a mediados del siglo XVIII, se llevó a cabo otra copia ( $\mathrm{M}=$ Colección Mecolaeta, Biblioteca Nacional de Madrid, ms. 13149), derivada de $\mathrm{F}$, aunque con algunos retoques procedentes de ${ }^{*} \mathrm{Q}$; de esta copia se desgajaron algunos folios, que ahora están en la biblioteca del Monasterio de Silos (Archivo de la Congregación de San Benito de Valladolid, t. 36). En M faltan el Sacrificio de la Misa, la Vida de Santa Oria y la Vida de Santo Domingo de Silos.

Algunas obras, además, presentan una tradición manuscrita más compleja:

La Vida de Santo Domingo de Silos es la obra de Berceo de tradición manuscrita más rica, pues a las copias que contienen todas las obras del autor, se añaden dos manuscritos individuales (Monasterio de Silos, ms. 12, hacia 1240 y $H$, Real Academia de la Historia, ms. 12-4-1, hacia 1360) y una edición de 1736, basada en la copia de Silos y completada con los otros testimonios medievales conservados $(\mathrm{H}$ y F).

Los loores de Nuestra Señora se han conservado - como otras obras de Berceo- gracias a las dos copias del siglo XVIII; no obstante, hay que señalar que el texto de Los loores de una de las copias dieciochescas se encuentra repartido entre sendos fragmentos en la Abadía de Santo Domingo de Silos (Archivo de los Benedictinos de la Congregación de Valladolid, t. 36, ff. 131r-138v, para las estrofas 1-156) y en la Biblioteca Nacional de Madrid (ms. 13149, ff. 65r-67v, para las estrofas $157-175$ y 196-233, y f. 65 bis para las estrofas 176-195). La otra copia del siglo XVIII no ha sufrido semejante desmembración y se conserva en la Abadía de Silos (ms. 93, ff. $84 \mathrm{v}-97 \mathrm{v})$.

La tradición manuscrita de la colección de los Milagros de Nuestra Señora - con un total de 911 cuadernas - sigue de cerca el stemma fijado para las demás obras de Berceo, aunque la desmembración de los códices haya provocado que no se conserve el texto completo en ninguno de los tres manuscritos que contienen la obra: una copia del siglo XVIII (ms. Ibarreta, Abadía de Santo Domingo de Silos, ms. 93) es la más completa, pues sólo presenta dos lagunas (que afectan a las estrofas 143-145 y 513-552). 
La otra copia dieciochesca $(\mathrm{M})$ contiene las estrofas $1-415$ y $615-911$, con lo que presenta una laguna de 200 estrofas; sin embargo, esta copia tiene el interés de transcribir dos veces la Introducción (estr. 1-46) según los dos códices distintos medievales (el perdido ${ }^{*} \mathrm{Q}$ y F). De F, hacia 1325 , se han conservado además tres fragmentos (dos en la Real Academia Española, mss. 4 y $4 \mathrm{~b}$ y en la biblioteca particular de la familia de D. Antonio Manrique de Lara, en Santo Domingo de la Calzada) que, en su conjunto, contienen completas las estrofas 522-911, mientras que las 521 estrofas restantes tienen numerosas lagunas que afectan a las 74 primeras coplas y a otras 85 más.

Se conserva El sacrificio de la misa en dos manuscritos: uno, fragmentario, de hacia 1290 (B, Biblioteca Nacional de Madrid, ms. 1533), contiene las estrofas 1-250c; el otro es la copia dieciochesca de Ibarreta, que copia del perdido ${ }^{*} \mathrm{Q}$ (mediados del siglo XIII) las estrofas 1-128 y de $\mathrm{F}$ (hacia 1325) el resto de la obra:

Los Himnos se conservan en la copia del siglo XVIII realizada por Ibarreta y en el ms. 13149 de la Biblioteca Nacional de Madrid (reproduce el ms. F, de h. 1325, en el que se recogen dos copias del Veni Creator y del Tu Christe, y una sola del Ave Sancta María).

Ediciones: Gonzalo de Berceo, Poemas, Edición facsímil del manuscrito (siglo XIV) propiedad de la Real Academia Española, Madrid, Real Academia Española, 1983. Gonzalo de Berceo, Obras, Ed. B. Dutton. 5 vols., Londres, Tamesis Books, 1967-1981. Gonzalo de Berceo, Obra Completa. Coord. I. Uría, Madrid, Espasa-Calpe y Gobierno de La Rioja, 1992.

Bibliografía: C. García Turza, La tradición manuscrita de Berceo con un estudio filológico particular del ms. 1533 de la Biblioteca Nacional de Madrid, Logroño, Instituto de Estudios Berceanos, 1979. I. Uría, «Sobre la transmisión manuscrita de las obras de Berceo», Incipit, 1, 1981, págs. 13-23.

\subsection{El Libro de Alexandre}

Se ha conservado en dos manuscritos y un fragmento, además de un par de citas de escasa entidad en otros textos, todos ellos descritos ya por R. S. Willis en 1934:

Biblioteca Nacional de Madrid, Vitr. 5-10 (procedente de la Biblioteca de los Duques de Osuna; copia del siglo XIII, con 2511 estrofas).

Biblioteca Nacional de París (Esp. 488; copia de mediados del siglo $\mathrm{XV}$, contiene 2639 estrofas). 
El fragmento se localiza en el Archivo Ducal de Medinaceli (Sevilla; archivo histórico, 37-50; es una copia del siglo XIV de los 27 primeros versos del texto).

Las citas proceden de una obra póstuma de Francisco de Bivar (muerto en 1635), Marci Maximi Caesaraugustani, viri doctissimi continuatio Chronici omnimodae Historiae ab Anno Christi 430 (...) usque ad 612 quo maximus pervenit (Madrid, 1651), en la que copia las estrofas 787-93, 851 y $1167-68 \mathrm{~b}$ de un manuscrito hoy perdido que se hallaba en el monasterio de Bugedo (Burgos). La otra cita la constituyen las 18 estrofas (51-55, 57-58, 61, 66-67, $72,75-77,80-82$ y 84 insertas en la Crónica de don Pero Niño o Victorial (entre 1431 y 1435), de Gutierre Díez de Games, que discrepan de las transmitidas por los manuscritos de Madrid y París, lo que hace pensar que Games conocía un códice distinto (que podría ser el de Bugedo u otro distinto). Las diferencias existentes entre los dos manuscritos y el fragmento o las citas son considerables, a la vez que la brevedad de estos testimonios apenas permite deducir nada, por lo que no resulta viable establecer un stemma de la obra; en todo caso, se debe pensar que el manuscrito de París y el de Madrid pertenecen a dos ramas de la tradición muy distantes entre sí; que el desaparecido códice de Bugedo pertenecía a otra rama, y que las citas contenidas en el Victorial y el fragmento de Medinaceli derivan, posiblemente, de otra copia.

Ediciones: El Libro de Alexandre, ed. R. S. Willis, Princeton, University Press, 1934 [repr., New York, Kraus, 1976]. Gonzalo de Berceo, El Libro de Alexandre, ed. D. A. Nelson, Madrid, Gredos, 1979. El Libro de Alexandre, ed. J. Cañas, Madrid, Cátedra, 1988.

Bibliografia: I. Michael, «Estado actual de los estudios sobre el El Libro de Alexandre», Anuario de Estudios Medievales, 2, 1965, págs. 581-595.

\subsection{El Libro de Apolonio}

El anónimo Libro de Apolonio se conserva en un manuscrito único, copiado en el siglo XIV (K.III.4 de la Biblioteca del Monasterio de El Escorial), aunque el original se suele situar a mediados del siglo XIII; en el mismo códice se encuentran el Libro de la infancia y muerte de Jesús y la Vida de Santa María Egipciaca.

Ediciones: El Libro de Apolonio: An Old Spanish Poem. Ed. C. Marden, part. I, Text and Introduction. Ed. corr., Princeton, University Press, 1937 
[repr., Milwood, Kraus, 1976]. El Libro de Apolonio, Ed. G. B. de Cesare, Milano, Cisalpina, 1974. El Libro de Apolonio. Ed. M. Alvar, 3 vols., Madrid, Fundación Juan March-Castalia, 1976. El Libro de Apolonio. Ed. M. Alvar, Barcelona, Planeta, 1984. El Libro de Apolonio. Ed. P. Caraffi. Parma, Pratiche, 1991. El Libro de Apolonio. Ed. D. Corbella, Madrid, Cátedra, 1992.

\subsection{El Poema de Fernán González}

El Poema de Fernán González se ha conservado en un manuscrito casi completo (752 cuadernas) y en varios fragmentos de diverso carácter. El texto más extenso forma parte de un códice copiado en la segunda mitad del siglo XV (Monasterio de El Escorial, ms. b.IV.21, folios 136r-190v); es la última obra contenida en un manuscrito de interés porque reúne obras de carácter didáctico o moralizante: los Proverbios morales, de Sem Tob de Carrión, el Tratado de la doctrina de Pedro de Veragüe; una Dança de la muerte y una versión ampliada de la Revelación de un ermitaño (o Disputa del cuerpo y el ánimo). Todas ellas forman parte del Mester de Clerecía, ya en decadencia desde finales del siglo XIV.

Además, veintiséis estrofas del Poema de Fernán González fueron copiadas por fray Gonzalo de Arredondo en la Crónica de Fernán González (estr. 158-170 y 195-207; estas últimas estrofas son citadas también en una Historia de Fernán González, anónima, compuesta en la última década del siglo XV y presentada a Carlos V en 1514. Otras cuatro estrofas fueron impresas por Gonzalo Argote de Molina en Sevilla, en 1575, como apéndice a su edición de El Conde Lucanor (estrofas 170-174): en el texto del erudito andaluz figura un verso (et de la otra parte Fitero fondon) que no aparece en el manuscrito Escurialense. Puede que no sea mera coincidencia que el texto citado por Arredondo en su Crónica termine, exactamente, donde comienza la cita de Argote: nada impediría que se tratara de un mismo manuscrito. En cualquier caso, resulta obvio que el manuscrito conservado en El Escorial era distinto del original utilizado por Argote. Se podría añadir, además, que en la biblioteca de Fernando Colón (n. ${ }^{\circ} 2230$ ) había un manuscrito del Poema, comprado en Roma en 1515, distinto también del códice Escurialense. Pero de nuevo hay que advertir que el texto de la biblioteca Colombina - hoy perdido- podría ser el mismo que utilizó Arredondo y que sesenta años más tarde estaba en propiedad de Argote, también en Sevilla.

Por último, hay que indicar que recientemente se ha descubierto un fragmento de 16 versos mutilados, que coinciden con la «oración de agonizantes» del Poema; se encuentran en una teja del antiguo tejado de la ermita 
de Santa Marina de Villamartín de Sotoscueva (Burgos), que fue construida a principios del siglo XIV: al tratarse de una oración, no se puede deducir que derive directamente del texto, aunque las abundantes coincidencias formales así permiten pensarlo.

El Poema de Fernán González es copia de un texto anterior perdido.

Ediciones: Poema de Fernán González, edic. facsímil, Burgos, Ayuntamiento, 1989. C. Marden, Poema de Fernán González, Baltimore, John Hopkins Press, 1904. R. Menéndez Pidal, Poema de Fernán González, en Reliquias de la poesía épica española, Madrid, Espasa-Calpe, 1951, págs. 34-180. E. Polidori, Poema de Fernán González, Tarento, 1961; Roma, 1962. J. Victorio, Poema de Fernán González, Madrid, Cátedra, 1981. M. A. Pérez Priego, Poema de Fernán González. (Edic. modernizada), Madrid, Alhambra, 1986. H. Salvador Martínez, Poema de Fernán González, Madrid, Espasa-Calpe (Austral, 195), 1991.

Bibliografía: C. Alvar, "Tipología de la tradición de los cantares de gesta», en Actes du XIè Congrès International de la Société Rencesvals, 2 vols., Barcelona, Real Academia de Buenas Letras, 1990, págs. 395-423.

\section{LITERATURA DIDÁCTICA Y MORALIZANTE}

\subsection{Sermones y ejemplos}

Bibliografia general: Medieval Sermon Studies Newsletter. Coventry, 1977. F. C. Tubach, Index exemplorum. A Handbook of Medieval Religious Tales, Helsinki, 1969. J. B. Schneyer, Repertorium der lateinische Sermones des Mittelalters für die Zeit vom 1150-1350, 9 vols., Münster, 1969-1980. C. Delcorno, «Rassegna di studi sulla predicazione medievale e umanistica (19701980)», Lettere italiane, 33, 1981, págs. 235-276. Cl. Bremond, J. Le Goff y J.-Cl. Schmitt, L'«exemplum» (Typologie des sources du Moyen Age occidental, 40), Turnhout, Brepols, 1982. M. G. Briscoe, Artes praedicandi (Typologie des sources du Moyen Age occidental, 61), Turnhout, Brepols, 1992.

\subsection{Máximas y proverbios}

Bibliografia general: W. Bonser-T.A. Stephens, Proverb Literature: A Bibliography of Works Relating to Proverbs, Londres, 1930. O. E. Moll, Sprichwörterbibliographie, Frankfurt a. M., 1958. W. Mieder, International Proverb Scholarship. An annoted Bibliography, New York-Londres, 1982. 


\subsubsection{Libro de los buenos proverbios}

Se conserva en tres manuscritos:

Escorial, L.III.2, fin s. XIII.

Escorial, h. III.1, s. XV.

Salamanca, Biblioteca Universitaria, ms. 1763, fin. s. XV.

Existe un fragmento en la Biblioteca Nacional de Madrid, ms. 9248.

Los dos manuscritos escurialenses pertenecen a la misma familia; los tres códices incluyen, también, el Poridat de poridades; en el códice h. III. 1 hay además otros textos didácticos: Castigos de los sabios y filósofos (o Flores de Philosophia); Capitulo del filósofo que llamaban Segundo; Capitulo cómo los fijos deven onrrar al padre; Capitulo de las hedades que fueron fasta la venida de Ihesu Christo; Capitulo de las palabras de Eclesiastés, fijo de David y Capítulo de las palabras de sapiencia que dixo Eclesiastés (incompleto). El códice salmantino incluye varios textos didácticos o moralizantes: Bocados de oro, Libro de los cien capitulos y Calila e Dimna.

Edición: H. Sturm, The Libro de los buenos proverbios, Lexington, Kentucky University Press, 1971.

Bibliografia: J. K. Walsh, «Versiones peninsulares del Kitab adab al-Falasiya de Hunayn ibn Ishaq. Hacia una reconstrucción del Libro de los buenos proverbios», Al-Andalus, 41, 1976, págs. 355-384.

\subsubsection{Bocados de oro (o Bonium)}

Se han conservado abundantes manuscritos con el texto, todos ellos del siglo XV, frecuentemente asociados con el texto de la Donzella Teodor o con otras obras de carácter didáctico-moralizante:

Escorial a. IV. 9 (con textos agustinianos o pseudo-agustinianos).

Escorial e. III. 10 (con Segundo y Adriano).

Escorial h.III.6 (con la Donzella Teodor).

Biblioteca Bartolomé March, Madrid, 20/4/1.

Biblioteca Nacional de Madrid, ms. 6545 (con Poridat de poridades).

Biblioteca Nacional de Madrid, ms. 6936 (con Castigos y dichos de sabios, Sermones y el Invencionario de Alfonso de Toledo).

Biblioteca Nacional de Madrid, ms. 8405 (con Libro de los cien capitulos).

Biblioteca Nacional de Madrid, ms. 9204.

Biblioteca Nacional de Madrid, ms. 17822 (con la Donzella Teodor). 
Biblioteca Nacional de Madrid, ms. 17853 (con la Donzella Teodor).

Salamanca, Biblioteca Universitaria, ms. 1763 (con el Libro de los cien capitulos, el Libro de los buenos proverbios, Poridat de las poridades y Calila e Dimna).

Salamanca, Biblioteca Universitaria, 1866 (con la Donzella Teodor).

Biblioteca Lambert Mata de Ripoll.

Biblioteca Universitaria de Santiago de Compostela.

Se conservan un par de fragmentos en el Escorial h.III.24 y en la Biblioteca Menéndez Pelayo, en Santander, ms. 53.

El texto fue impreso en Sevilla, por Meinardo Ungut y Estanislao Polono, 1495; en Toledo (1510) y Valladolid (1527).

Los manuscritos del Escorial e.III.10, de la Biblioteca Nacional de Madrid 9204 y de las colecciones de Bartolomé March y Lambert Mata pertenecen todos a una misma familia, en la que se agrupan también los impresos. El resto de los manuscritos forman parte de otra rama de la tradición textual.

Edición: M. Crombach, Bocados de oro, Bonn, Romanischen Seminar der Universität Bonn, 1971.

Bibliografia: B. Taylor, «Old Spanish Wisdom Texts: Some Relationships», $C, 14,1985$, págs. 71-85; M. Haro Cortés, «Un nuevo testimonio fragmentario de los Bocados de oro», RLM, 8, 1996, págs. 9-25.

\subsubsection{Libro de los cien capitulos (o Dichos de sabios)}

El texto se conserva en los siguientes manuscritos:

Biblioteca Nacional de Madrid, ms. 6608 (con el Libro del consejo y de los consejeros, atribuido a Pedro Gómez Barroso).

Biblioteca Nacional de Madrid, ms. 8405 (con Bocados de oro).

Biblioteca Nacional de Madrid, ms. 9216 (con el Libro del consejo y de los consejeros y los Proverbios morales de Santob).

Salamanca, Biblioteca Universitaria, ms. 1763 (con los Bocados de oro, el Libro de los buenos proverbios, Poridat de las poridades y Calila e Dimna).

Santander, Biblioteca Menéndez y Pelayo, M/108.

Edición: Libro de los cien capitulos, ed. A. Rey, Bloomington, Indiana University Press, 1960. 


\subsubsection{Flores de Filosofia}

Se ha conservado, al menos, en siete códices, y hay noticias de otra copia más, hoy perdida:

Biblioteca Nacional de Madrid, ms. 9266.

Biblioteca Nacional de Madrid, ms. 9428.

Escorial h.III.1 (con otros textos didácticos o sapienciales: Poridat de las poridades, Capítulo del filósofo que llamaron Segundo; Capítulo cómo los fijos deven onrrar al padre; Capitulo de las hedades que fueron fasta la venida de Ihesu Christo; Capitulo de las palabras de Eclesiastés, fijo de David y Capitulo de las palabras de sapiencia que dixo Eclesiastés, incompleto).

Escorial S-II-13 (donde se encuentra acompañado por textos religiosos doctrinales).

Hispanic Society of New York HC371/217.

Biblioteca de Palacio II. 569; se incluye en un códice de finales del siglo XV, junto con el Libro de las batallas de Vegecio.

Escorial \&.II.8, en el que se encuentra esta obra con otros tratados, como el Libro de los doce sabios o La doctrina del hablar y del callar de Albertano de Brescia. Es copia de finales del siglo XV o del siglo XVI.

Escorial X.II.12. Es copia del siglo XVI.

La copia del texto que se incluía en el Cancionero de Martínez de Burgos está en paradero desconocido, como el resto del cancionero.

Edición: H. Knust, Dos obras didácticas y dos leyendas, sacadas de manuscritos de la Biblioteca del Escorial, Madrid, Sociedad de Bibliófilos Españoles, 1878.

Bibliografía: J. M. Lucía Megías, «Un nuevo testimonio de Flores de filosofia: el ms. II.569 de la Biblioteca del Palacio Real de Madrid», en RLM, 6, 1994, págs. 211-223.

\subsubsection{Segundo y Adriano}

El texto se conserva en tres códices:

Salamanca, Biblioteca Universitaria, ms. 1763 (con los Bocados de oro, el Libro de los cien capitulos, el Libro de los buenos proverbios, Poridat de las poridades y Calila e Dimna).

Escorial h.III.1 (con otros textos didácticos o sapienciales: Poridat de las poridades, Flores de filosofia; Capitulo cómo los fijos deven onrrar al padre; Capitulo de las hedades que fueron fasta la venida de Ihesu Christo; Capitulo de las palabras de Eclesiastés, fijo de David y Capitulo de las palabras de sapiencia que dixo Eclesiastés).

Escorial e.III.10 (con los Bocados de oro). 
Edición: H. Knust, Mittheilungen aus dem Eskurial, Tübingen, Bibliothek des litterarischen Vereins in Stuttgart, 1879, págs. 373-387.

Bibliografia: M. Morrás, «Tractado de Segundo filósofo que fue en Athenas: Otro manuscrito inédito», BHS, 67, 1990, págs. 279-284.

\subsubsection{Teodor la donzella}

La historia de la doncella Teodor cuenta con dos ramas diferentes en la tradición manuscrita castellana, que aumentarán hasta seis gracias al éxito de los impresos.

Pertenecen a una misma familia los siguientes manuscritos:

Escorial h.III.6.

Biblioteca Nacional de Madrid, ms. 17853.

Biblioteca Nacional de Madrid, ms. 17822.

Biblioteca Universitaria de Salamanca, ms. 1866.

A la otra rama pertenece el ms. 9055 de la Biblioteca Nacional de Madrid. Todos los textos fueron copiados en el siglo XV.

La obra fue impresa alrededor de 1500 en Toledo, por Pedro Hagenbach y pocos años más tarde, hacia 1516-1520, en Sevilla por Juan Varela de Salamanca.

Otra edición sevillana, esta vez de Jacobo Cromberger, h. 1526-1528 presenta una puesta al día con materiales ajenos a la tradición de la obra: el éxito fue grande, y este texto se reprodujo en 1533, ¿1535?, 1543, 1545, 1554, y en una edición de Segovia, sin año...

La popularidad de la historia llevó a nuevas revisiones y alteraciones: en Zaragoza, Pedro Hardoyn imprimió una versión nueva (1540), con abundantes materiales procedentes del Infante Epitus; esta versión es la base de las que hicieron Juan Gracián en Alcalá de Henares, 1607 y Salvador de Viader en Cuenca, 1628. La última elaboración conocida del texto fue llevada a cabo por Francisco Pinardo y publicada por Bernardo Nogués en Valencia, 1643. En el siglo XVIII se editó, al menos, tres veces, y unas veinte en el siglo XIX.

Ediciones: W. Mettmann, La historia de la doncella Teodor. Ein Spanisches Volksbuch arabischen Ursprungs. Untersuchung und kritische Ausgabe der ältesten bekannten Fassungen, Wiesbaden, Akademie der Wissenschaften und der Literatur, 1962. N. Baranda y V. Infantes, Narrativa popular de la Edad Media, Madrid, Akal, 1995. 


\subsubsection{Tratado del ynfante Phiteus (o Dichos del ynfante Epitus)}

Se conocen tres manuscritos medievales de esta obra:

Biblioteca Nacional de Madrid, ms. 10011.

British Library, Egerton 939.

Biblioteca Nacional de Madrid, ms. 17657.

Al final del ms. del Poema del Cid (Biblioteca Nacional de Madrid, Vitr. 7-17) se conservan unas líneas del mismo texto.

Salvo el códice 10011 de Madrid, el resto de los testimonios están emparentados.

En 1492 (Zaragoza, por Pablo Hurus) se imprimieron los Dichos, con notables modificaciones, que influirán más tarde en las diferentes ediciones de la Doncella Teodor. Se conocen, además, otros impresos: Sevilla, ¿Juan Cromberger, h. 1535? y Burgos, Juan de Junta, 1540; es probable que hubiera una edición de la obra anterior a 1528 .

Ediciones: H. O. Bizzarri, Diálogo de Epicteto y el emperador Adriano, Madrid, Iberoamericana, 1995. D. Severin, «El ynfante Epitus: The Earliest Complete Castillian Version of the Dialogue of Epictetus and The Emperor Hadrian», BHS, 62, 1985, págs. 25-30.

\subsubsection{Poridat de las poridades}

Se conserva en cuatro manuscritos:

Biblioteca Nacional de Lisboa, ms. il. n. ${ }^{\circ}$ 46, segunda mitad del siglo XIII.

Escorial, ms. h. III.1, siglo XV.

Escorial, L.III.2, fin siglo XIII.

Biblioteca Nacional de Madrid, ms. 6545 (fragmento incluido en los Bocados de oro), siglo XIV.

Los dos manuscritos escurialenses pertenecen a la misma familia, y en los mismos códices se incluye, también, otro texto didáctico, el Libro de los buenos proverbios. Los manuscritos de Lisboa y Madrid forman parte de una familia diferente y están estrechamente emparentados entre sí, pues el texto de Madrid es copia - inexacta- del conservado en Lisboa.

Ediciones: LL. A. Kasten, Seudo Aristóteles, Poridat de las poridades. Madrid, 1957. H. O. Bizzarri, Pseudo-Aristóteles, Secreto de los secretos (Ms. BNM 9428), Buenos Aires, SECRIT, 1991. 
Bibliografia: M. Morrás, «Tractado de Segundo filósofo que fue en Athenas: Otro manuscrito inédito», $B H S, 67,1990$, págs. 279-284.

\subsubsection{Libro de los doze sabios (o Tratado de la nobleza y lealtad)}

Cinco manuscritos conservan la obra:

Biblioteca Nacional de Madrid, ms. 12733, de principios del siglo XV Escorial \&.II.8 (con otros tratados, como Flores de filosofia), fue copiado en los siglos XVII y XVIII (Biblioteca Nacional de Madrid, mss. 18653 y 9934, respectivamente).

Biblioteca Menéndez Pelayo, ms. 77 (del siglo XVI), está emparentado con el códice de la Biblioteca Nacional de Madrid, ms. 12733.

La obra fue impresa en Valladolid, por Diego de Gumiel, en 1502, cuyo texto está emparentado, también, con el manuscrito medieval madrileño.

Edición: J. K. Walsh, El Libro de los doze sabios o Tractado de la nobleza y lealtad [ca. 1237], Estudio y edición, Madrid, Real Academia Española, 1975.

\subsubsection{Castigos e documentos del rey don Sancho}

Se conocen cinco manuscritos y un breve fragmento de la obra del hijo de Alfonso X: glo XIV.

Escorial, Z.III.4 (con el Libro del consejo y de los consejeros), fin. si-

Biblioteca Nacional de Madrid, ms. 3995 (fin. siglo XIV).

Biblioteca Nacional de Madrid, ms. 6559 (con el Libro del consejo y de los consejeros), único representante de una versión extensa, fin siglo XIV.

Biblioteca Nacional de Madrid, ms. 6603 (primera mitad del siglo Xv).

Sigüenza, Seminario Conciliar, mediados del siglo XIV, es la copia más antigua.

El fragmento se encuentra en el Seminario de S. Jerónimo, de Burgos, $\mathrm{y}$ es de principios del siglo $\mathrm{XV}$.

Ediciones: Text and Concordances of Escorial Ms. Z.III.4 "Castigos e documentos del rey Sancho IV», Ed. M. Bailey, Madison, HSMS 1992 [microfichas]. Texto y Concordancias de la Biblioteca Nacional, Ms. 6603 
«Castigos e documentos» and "Libro del consejo e de los consejeros». Ed. J. Zemke. Madison, HSMS, 1992 [microfichas]. A. Rey, Castigos e documentos para bien vivir, ordenados por el rey don Sancho IV, Bloomington, Indiana University Press, 1952.

Bibliografía: C. Alvar y J. M. Lucía (ed.), La literatura en la época de Sancho $I V$, Alcalá de Henares, Universidad, 1996.

\subsubsection{Libro del consejo e de los consejeros}

Se conservan cuatro manuscritos:

Escorial, Z.III.4 (con los Castigos e documentos de Sancho IV).

Biblioteca Nacional de Madrid, ms. 6559 (también con los Castigos; de finales del siglo XIV).

Biblioteca Nacional de Madrid, ms. 6608 (con el Libro de los cien capitulos).

Biblioteca Nacional de Madrid, ms. 9216 (con el Libro de los cien capitulos y los Proverbios morales de Santob de Carrión; el manuscrito es de mediados del siglo Xv).

Edición: A. Rey, Maestre Pedro, Libro del consejo e de los consejeros, Zaragoza, Universidad, 1962.

\subsubsection{Calila e Dimna}

Se conservan tres manuscritos y un fragmento del Calila e Dimna:

Escorial, h.III.9, de princ. siglo xv.

Escorial, X.III.4 (con la Semeiança del mundo isidoriana y el Invencionario de Alfonso de Toledo, fechado en 1467).

Biblioteca Universitaria de Salamanca, ms. 1763 (incompleto): códice facticio que incluye otras obras didácticas o sapienciales (Bocados de oro, Libro de los cien capitulos, Libro de los buenos proverbios y Poridat de poridades).

Los dos códices escurialenses derivan de la versión alfonsí.

El fragmento está en la Biblioteca de la catedral de Oviedo.

Edición: J. M. Cacho Blecua - M. ${ }^{a}$ J. Lacarra, Calila e Dimna, Madrid, Castalia, 1984.

Bibliografía: I. Montiel, Historia y bibliografia del libro de Calila e Dimna, Madrid, Editora Nacional, 1975. 
4.2.13. Libro de los engaños e asayamientos de las mugeres (o Sendebar)

Manuscrito único:

Real Academia Española, 15 (llamado códice Puñonrostro, contiene también El conde Lucanor y el Lucidario).

Ediciones: M. ${ }^{a}$ J. Lacarra, Sendebar, Madrid, Cátedra, 1989. J. Fradejas Lebrero, Sendebar o Libro de los engaños de las mujeres. (Versión modernizada), Madrid, Castalia (Odres Nuevos), 1990. E. Vuolo, Libro de los engaños, Nápoles, Liguori, 1980.

Bibliografia: H. R. Runte, J. K. Wikeley y A. Farrell, The «Seven Sages of Rome» and the "Book of Sindibad». An Analitical Bibliography, New York-Londres, 1974. A. González Palencia, Versiones Castellanas del "Sendebar», Madrid-Granada, CSIC, 1946. V. de la Torre Rodríguez, «Filiación de las versiones castellanas del ciclo Siete Sabios de Roma variantes del Sendebar occidental», RFE, 72, 1992, págs. 103-115.

\subsubsection{Barlaam e Josafat}

Tres manuscritos:

Salamanca, Biblioteca Universitaria, ms. 1877 (copiado en 1470; el códice contiene otros textos didáctico-moralizantes y versiones de obras artúricas.

Biblioteca Nacional de Madrid, ms. 18017.

Estrasburgo, Bibliothèque Universitaire, ms. 1829 (es el más breve de los tres; se trata de una versión directa del epítome latino).

Edición: Barlaam e Josafat; ed. J. E. Keller y R. Linker, Madrid, CSIC, 1979.

\subsection{La Fazienda de Ultramar}

Manuscrito único:

Biblioteca Universitaria de Salamanca, ms. 1997; entre 1200 y 1210.

Edición: Almerich, La Fazienda de Ultramar; ed. de M. Lazar, Salamanca, Universidad, 1965. 


\subsection{El Lucidario}

Siete manuscritos:

Biblioteca Nacional de Madrid, ms. 3369 (con Semeiança del mundo; es de 1455).

Biblioteca Universitaria de Salamanca, 1958, siglo XV.

Biblioteca de Palacio, en Madrid, ms. 793 (acabado en 1470).

Real Academia Española, ms. 15 (es el códice Puñonrostro, en el que se copió también El conde Lucanor y el Libro de los engaños; de finales del siglo Xv).

Biblioteca Nacional de Madrid, ms. 6958 (con la Visión Delectable de Alfonso de la Torre; acabado en 1531).

Academia de la Historia, Madrid, códice 101 (Cortes, 26), en el mismo manuscrito hay un tratado de S. Jerónimo (Scala coeli) y un Sermón sobre el avenimiento del Anticristo; es del siglo XV.

En la Biblioteca de Palacio hay una copia moderna: ms. 168 (siglo XVIII).

Los tres primeros manuscritos citados están emparentados de forma muy cercana.

Edición: R. P. Kinkade, Los «Lucidarios» españoles, Madrid, Gredos, 1968.

Bibliografía: C. Alvar y J. M. Lucía (eds.), La literatura en la época de Sancho IV. Alcalá de Henares, Universidad, 1996.

\section{Alfonso X}

Bibliografía general: Noticiero alfonsí, Wichita State University, Wichita (Kansas), desde 1982. R. J. González-Casanovas (editor), «Alfonso X Studies 1983-1994: General Bibliography with Analytical Tables», Exemplaria Hispanica, 3, 1993-1994, págs. 1-139.

Manuscritos de la cámara regia:

Libros del saber de astronomía: Biblioteca Universitaria de Madrid, ms. 156.

Lapidario e Libro de las formas y de las imágenes: Escorial, h.I.15; Escorial, h.I.16.

Picatrix: Biblioteca Vaticana, Reg. Lat. 1283.

Libro de las cruces: Biblioteca Nacional de Madrid, ms. 9294.

Axedrez, dados e tablas: Escorial, T.I.6.

Cánones de Albateni: Bibliothèque de l'Arsenal, ms. 8322 (el códice contiene también el Libro del cuadrante señero, las Tablas de Albateni y las Tablas de Zarquiel). 
Grande e General Estoria: Biblioteca Nacional de Madrid, ms. 819 (Parte I) y Vaticano, Urb. Lat. 539 (Parte IV).

Estoria de España: Escorial Y.I.2; Escorial X.I.4.

Cantigas de Santa Maria: Biblioteca Nacional de Madrid, ms. 10069 (procede de la Catedral de Toledo), Escorial T.I.I. y b. I. 2; Biblioteca Nazionale di Firenze, B.R. 20 (ant. II.1.213).

Libro conplido de los judizios de las estrellas de Aly Aben Ragel: Biblioteca Nacional de Madrid, ms. 3065.

Primera Partida: British Library, Add. 20787. Tercera Partida: Escorial, P. III.2.

Tratados legales: Escorial, Z.III.13.

Bibliografia: Concordances and texts of the Royal Scriptorium manuscripts of Alfonso X el Sabio, por L1. Kasten y J. Nitti, Madison, HSMS, 1978 [Microfichas].

\subsection{Libros astronómicos, astrológicos y de magia}

Ediciones: Alfonso X, El Lapidario, [ed. facsímil del ms. Escorial h.I.15], 2 vols., Madrid, Edilán, 1982. Alfonso el Sabio, Libros de ajedrez, dados y tablas, [ed. facsímil del ms. Escorial, T.I.6], 2 vols., Valencia, Vicent García, 1987. Alfonso X el Sabio, Astromagia. (MS. Reg. Lat. $1283^{a}$ ), ed. A. D'Agostino, Napoli, Liguori, 1992. Alfonso el Sabio, Lapidario and Libro de las formas \& ymagenes, ed. R. C. Diman y L. W. Winget, Madison, HSMS, 1980. Alfonso X, El Lapidario (según el manuscrito escurialense H.I.15), ed. S. Rodríguez M. Montalvo, Madrid, Gredos, 1981. Aly Aben Ragel, El Libro conplido en los iudizios de las estrellas. Traducción hecha en la corte de Alfonso el Sabio, ed. G. Hilty, Madrid, Real Academia Española, 1954. Alfonso el Sabio, Libro de las Cruzes, ed. LL. A. Kasten y L. B. Kiddle, MadridMadison, CSIC, 1961. Alfonso X, Libros del saber de astronomía, ed. M. Rico y Sinobas, 5 vols., Madrid, Tipografía Eusebio Aguado, 1863-1867. Alfonso X, Los cánones de Albateni, ed. G. Bossong, Tübingen, Max Niemeyer, 1978. Alfonso X, Les tables alphonsies avec les Canons de Jean de Sa$x e$, éd. et trad. E. Poulle, París, Centre National de la Recherche Scientifique, 1984. Alfonso el Sabio, Libros de acedrex, dados e tablas. Das Schachzabelbuch König Alfons des Weisen, ed. A. Steiger, Ginebra-Zurich, Droz, 1941.

Bibliografía: A. J. Cárdenas, «A Survey of Scholarship on the Scientific Treatises of Alfonso X el Sabio", C, 10, 1982, págs. 231-247. F. J. Carmody, Arabic Astronomical and Astrological Sciences in Latin Translation: A Critical Bibliography, Berkeley-Los Angeles, University Press, 1956. A. J. Cárdenas, «Hacia una edición crítica del Libro del saber de astrología de Alfonso X: Estudio codicológico actual de la obra regia (mutilaciones, fechas y motivos)», en Homenaje a Pedro Sáinz Rodríguez, vol. II. Madrid, Fundación Universitaria Española, 1986, págs. 111-120. 


\subsection{La obra historiográfica}

Ediciones: Alfonso X, Primera Crónica General de España, ed. R. Menéndez Pidal, vol. I, Madrid, Gredos-Seminario Menéndez Pidal, 1955; vol. II, 3. ${ }^{a}$ ed., Madrid, Gredos-Seminario Menéndez Pidal, 1977. I. Fernández-Ordóñez, Versión crítica de la Estoria de España. Estudio y Edición desde Pelayo hasta Ordoño II, Madrid, Seminario Menéndez Pidal-Universidad Autónoma de Madrid, 1993. Alfonso X, General Estoria, Primera Parte, ed. A. García Solalinde, Madrid, Junta para la Ampliación de Estudios, 1930. Alfonso X, General Estoria, Segunda Parte, ed. A. García Solalinde, Ll. Kasten y V. R. B. Oelschläger, 2 vols., Madrid, Consejo Superior de Investigaciones Científicas, 1957-61. Alfonso X, General Estoria, Tercera Parte (IV. Libros de Salomón), ed. P. Sánchez-Prieto Borja y B. Horcajada Diezma, Madrid, Gredos, 1994. Alfonso X, General Estoria IV. La historia novelada de Alejandro Magno, ed. T. González Rolán y P. Saquero SuárezSomonte, Madrid, Universidad Complutense, 1982.

\subsection{Actividad jurídica y legislativa}

Ediciones: Alfonso el Sabio, Setenario, ed. K. H. Vanderford, Barcelona, Crítica, 1984. Alfonso X, Setenario. Texto jurídico atribuido al Rey de Castilla don Alfonso, el Sabio, ed. R. MacDonald, Madison, HSMS, 1990. Las Siete Partidas del Sabio rey don Alonso el nono, nuevamente glosadas por el Licenciado Gregorio López [...]. (1555), Andrea de Portonaris. [Ed. facsímil, 3 vols., Madrid, Boletín Oficial del Estado, 1984]. Alfonso X, Primera Partida, según el manuscrito Add 20787 del British Museum, ed. J. A. Arias Bonet, Valladolid, Universidad, 1975. Alfonso X, Primera Partida: ms. HC 397/573 Hispanic Society of America, edic. F. Ramos Bossini, Granada, Caja General de Ahorros, 1984. Alfonso X, Partida Segunda de Alfonso X el Sabio. Manuscrito 12794 de la B.N., ed. A. Juárez Blanquer y A. Rubio Flores, Granada, Impredisur, 1991. Opúsculos legales del rey don Alfonso el Sabio, Madrid, 1836. Alfonso X, Espéculo, ed. G. Martínez Díez y J. M. Ruiz Asensio, Ávila, Fundación C. Sánchez Albornoz, 1985. Alfonso X, el Sabio, Espéculo. Ms. 10.123 de la BNM, ed. R. A. MacDonald, Madison, HSMS, 1989. Alfonso X, Fuero Real, ed. G. Martínez Díez con la col. de J. M. Ruiz Asensio y C. Hernández Alonso, Ávila, Fundación C. Sánchez Albornoz, 1988. Alfonso X, Fuero Real, ed. A. Palacios Alcaine, Barcelona, PPU, 1991. Jacobo de Junta, el de las Leyes, Oeuvres, I: Summa de los nueve tiempos de los pleitos, ed. J. Roudil, Paris, Klinksieck, 1986.

Bibliografía: J. R. Craddock, The Legislative Works of Alfonso X el Sabio: A Critical Bibliography, Londres, Cutler \& Grant, 1986. 
6. LA PROSA HASTA MEDIADOS DEL SIGLO XIV

\subsection{La leyenda de Troya}

La Historia troyana en prosa y verso se conserva en dos manuscritos:

Biblioteca Nacional de Madrid, ms. 10146, de principios del siglo XIV. Escorial, ms. L.II.16, es de finales del siglo XIV.

En ambos casos el texto está incompleto, y parece haber servido como enlace entre dos partes de la versión de Alfonso XI del Roman de Troie de Benoit de Saint-Maure.

La Historia Troyana se conserva en tres manuscritos:

Escorial, h.I.6 (fechado el 31 de diciembre de 1350).

Biblioteca Menéndez Pelayo, Santander, M/558, de finales del siglo XIV.

Biblioteca Nacional de Madrid, ms. 10146, del siglo XV.

Los textos, incompletos, copian fragmentos de una versión gallega que se realizó sobre un original castellano, hoy perdido.

Ediciones: R. Menéndez Pidal, Historia troyana en prosa y verso, Madrid, Junta para la Ampliación de Estudios, 1934. K. M. Parker, Historia Troyana, Santiago de Compostela, CSIC, 1975. R. Lorenzo, Crónica Troiana, La Coruña, Fundación Barrié de la Maza, 1985.

Bibliografia: A. Rey y A. García Solalinde, Ensayo de una bibliografía de las leyendas troyanas en la literatura española, Bloomington, Indiana University Press, 1942. A. García Solalinde, «Las versiones españolas del Roman de Troie», RFE, 3, 1916, págs. 121-165.

\subsection{Las traducciones de materia artúrica}

Del Tristán se conservan dos manuscritos, ambos de finales del siglo XIV o comienzos del $\mathrm{XV}$ :

Biblioteca Nacional de Madrid, ms. 20262 (n. ${ }^{\circ}$ 19), es un solo folio que sigue la versión en prosa recopilada por Rusticiano de Pisa y que posiblemente fue utilizado para las versiones impresas.

Vaticano 6428, en una mezcla lingüística de castellano y aragonés.

A los últimos años del siglo XV corresponde el fragmento de las «Cartas de Tristán e Iseo», Biblioteca Nacional de Madrid, ms. 22021, ff. 8v-12v. 
El Tristán de Leonís se imprimió, siguiendo un texto próximo al del Vaticano ms. 6428, en Valladolid, 1501 y Sevilla, 1528 y 1534 (ésta con adición de nuevos materiales).

La historia de Lanzarote se conserva en textos fragmentarios, versiones parciales o incompletas:

El segundo e tercero libro de don Lançarote del Lago, Biblioteca Nacional de Madrid, ms. 9611 (del siglo XvI, copia un original perdido de 1414; sigue el texto de la Vulgata).

El resto de los manuscritos o incunables se basan en la Post-Vulgata:

Salamanca, Biblioteca Universitaria, ms. 1877 (fechado en 1469-70), que incluye el Libro de José de Arimatea, la Estoria de Merlin y Lançarote, todos ellos incompletos.

Lope García de Salazar resume en su Libro de las bienandanzas e fortunas (entre 1471 y 1476) las tres ramas de la Post-Vulgata:

Madrid, Academia de la Historia, 9-10-2/2100 (ms. de 1492).

Biblioteca Nacional de Madrid, ms. 1634 (copia el anterior, siglo XVI).

El baladro del sabio Merlín con sus profecias fue impreso en Burgos, por Juan de Burgos, en 1498; La demanda del sancto Grial se imprimió en Toledo (Juan de Villaquirán, 1515) y en Sevilla, 1535. En portugués se conservan algunos textos vinculados con los castellanos.

Ediciones: "Carta de Iseo y respuesta de Tristán», ed. F. Gómez Redondo, Dicenda, 7, 1987, págs. 327-356. Cuento de Tristán de Leonis, ed. G. T. Northup, Chicago, University Press, 1928. Cuento de Tristán de Leonis: The Text and Concordances of Vaticana Ms 6428, ed. I. A. Corfis, Madison, HSMS, 1985. Libro del esforçado cavallero don Tristán de Leonis y de sus grandes hechos en armas, ed. A. Bonilla y San Martín, Madrid, Sociedad de Bibliófilos Madrileños, 1912 [fragmento del texto publicado en Valladolid, 1501]. Libro del esforçado cavallero don Tristán de Leonis y de sus grandes hechos en armas, ed. A. Bonilla y San Martín, Madrid, BaillyBaillière, 1907 [texto de la edición de Sevilla, 1528]. Spanish Grail Fragments: El Libro de Josep Abarimatia. La Estoria de Merlín, Lançarote, ed. K. Pietsch, 2 vols., Chicago, University Press, 1924-5. Baladro del sabio Merlin, ed. P. Bohigas, 3 vols., Barcelona, Selecciones Bibliófilas, 1957-61 [texto de la edic. de Burgos, 1498]. Baladro del sabio Merlín, ed. J García Morales, Madrid, Joyas Bibliográficas, 1956-60. Baladro del sabio Merlín, ed. A. Bonilla y San Martín, Madrid, Bailly-Baillière, 1907. Demanda del Sancto Grial, ed. A. Bonilla y San Martín, Madrid, Bailly-Baillière, 1907. [Texto de la edic. de Sevilla, 1535]. 
Bibliografía: H. L. Sharrer, A Critical Bibliography of Hispanic Arthurian Material, I: Texts: The Prose Romance Cycles, Londres, Grant \& Cutler, 1977. C. Alvar, «Poesía gallego-portuguesa y Materia de Bretaña: algunas hipótesis», en $O$ cantar dos trobadores, Santiago de Compostela, 1993, págs. 31-51. I. Castro, «Sobre a data da introdução na Península Ibérica do ciclo arturiano da Post-Vulgata», Boletim de Filologia, 28, 1993, págs. 81-98. W. J. Entwistle, Arthurian legend in the literatures of the Spanish Peninsula, Londres, J. M. Dent, 1925. id., "Geoffrey of Monmouth and Spanish Literature», $M L R, 17,1922$, págs. 381-391. M. ${ }^{a}$ R. Lida de Malkiel, Estudios de literatura española y comparada, Buenos Aires, EUDEBA, 1969, págs. 134-148.

M. ${ }^{a}$ L. Cuesta Torre, «Origen de la materia tristaniana: estado de la cuestión», Estudios humanísticos. Filología, 13, 1991, págs. 185-197. J. B. Hall, «A Process of Adaptation: The Spanish Versions of the Romance of Tristan», in The Legend of Arthur in the Middle Ages: Studies presented to A. M. Diverres, Cambridge, D. S. Brewer, 1983, págs. $76-85$ y $235-237$. H. L. Sharrer, «Malory and the Spanish and Italian Tristan Texts: The search for the missing link», Tristania, 4, 1979, págs. 37-43. Id., «Letters in the Hispanic Prose Tristan Texts», Tristania, 7, 198182, págs. 3-20. M. ${ }^{\mathrm{a}}$ L. Cuesta Torre, «La transmisión textual de Don Tristán de Leonís», RLM, 5, 1993, págs. 63-93.

\subsection{La Gran Conquista de Ultramar}

La Gran Conquista de Ultramar se conserva en cuatro mss. fragmentarios y en un impreso:

Biblioteca Nacional de Madrid, ms. 1187 (finales del siglo XIII o principios del XIV).

Biblioteca Nacional de Madrid, ms. 1920 (finales del siglo XIV o principios del Xv).

Biblioteca Nacional de Madrid, ms. 2454 (finales del siglo XIv, principios del $\mathrm{xV}$ ).

Salamanca, Biblioteca Universitaria, ms. 1698 (siglo xv).

Es posible que Biblioteca Nacional de Madrid, ms. 2454 y Salamanca, ms. 1698 formen parte de un mismo original desmembrado.

La Gran Conquista de Ultramar se imprimió en Salamanca, por Hans Giesser, en 1503. Según todo parece indicar, la tradición del texto se divide en dos ramas: en la primera se sitúan en igualdad de condiciones los mss. 1187 y 1920 de la Biblioteca Nacional de Madrid; en la otra, el resto de los testimonios conservados, siendo el ms. 2454 la fuente directa del impreso.

Ediciones: La Gran Conquista de Ultramar, edic. de G. T. Northup, Chicago, University Press, 1965. La Gran Conquista de Ultramar, ed. de L. Cooper, 4 vols., Bogotá, Instituto Caro y Cuervo, 1979. La Gran Conquista de Ultramar: Biblioteca Nacional MS 1187, ed. L. Cooper y F. M. Walt- 
man, Madison, HSMS, 1989. La Leyenda del Caballero del Cisne, ed. M. ${ }^{a}$ T. Echenique, Barcelona, Aceña, 1989.

Bibliografia: C. González, «Bibliografia de la La Gran Conquista de Ultramar», C, 17, 1986, págs. 102-108. F. M. Waltman y L. Cooper, The Text and Concordances of Biblioteca Nacional Manuscript 1187, Gran Conquista de Ultramar, Madison, HSMS, 1985. G. T. Northup, Guide to La Gran Conquista de Ultramar Materials, Chicago, University Press, 1965. A. Rey, «Las leyendas del ciclo carolingio en La Gran Conquista de Ultramar», RPh, 3, 1949-50, págs. 172-181.

\subsection{El Libro del Cavallero Zifar}

El Libro del Cavallero Zifar se conserva en dos mss. del siglo Xv:

Biblioteca Nacional de Madrid, ms. 11309.

Bibliothèque Nationale de Paris, Esp. 36.

Se imprimió en Sevilla, por Jacobo Cromberger, en 1512, edición que tomó como modelo un ms. hoy perdido. El códice madrileño pertenece a una rama de la tradición diferente a la de los textos de París y Sevilla, que proceden de un subarquetipo común.

Ediciones: Libro del Cavallero Zifar. Códice de París, Barcelona, Moleiro, 1996 [facsímil]. Libro del Cavallero Zifar, ed. C. P. Wagner, Michigan, University Publications, 1929 [reed. New York, Kraus, 1980]. Libro del Cavallero Zifar, ed. J. González Muela, Madrid, Castalia, 1982. Libro del Cavallero Zifar, ed. C. González, Madrid, Cátedra, 1983. Libro del Cavallero Zifar, ed. M.A. Olsen, Madison, HSMS, 1984.

Bibliografia: M. A. Olsen, «Tentative Bibliography of the Libro del Cavallero Zifar», C, 11, 1983, págs. 327-335. M. Harney, «The Libro del Cavallero Zifar: Recent editions and a recent monograph», $R P h, 43,1990$, págs. 569-601. J. M. Lucía Megías, «Un folio recuperado del Libro del Cavallero Zifar», RLM, 4, 1992, págs. 163-175. Id. «Los testimonios del Zifar», en Libro del Cavallero Zifar. Códice de París. Barcelona, Moleiro, 1996, págs. 95-136.

\section{El VERSO HASTA MEDIADOS DEL SIGLO XIV}

\subsection{Textos menores de la cuaderna vía}

El Dio alto se conserva en un ms. único, junto con el lamento Ay, Jherusalem y con los Diez Mandamientos; las tres obras proceden de ámbito 
judío o converso; el ms., de dos hojas, se encuentra en el Archivo Histórico Nacional, Diversos, Miscelánea, cajón 12, y es de finales del siglo XIV o principios del $\mathrm{XV}$.

Del Catón glosado hay un ms., Biblioteca Nacional de Madrid, ms. 4202 , del siglo $\mathrm{xV}$, en el que se reúnen otros textos de carácter didácticomoralizante; hubo otra versión, quizás del siglo XIII, que se ha conservado en incunables e impresos del siglo XVI.

La Vida de S. Ildefonso está en un manuscrito del siglo XV (Fundación Lázaro Galdiano, Madrid, 419) y en dos copias modernas (Biblioteca Nacional de Madrid, 5548 y Biblioteca Nacional de Madrid, 19161, de los siglos XVIII y XIX, respectivamente); no hay grandes divergencias entre todos los códices y tanto el medieval, como el del siglo XVIII recogen también la Leyenda Dorada de Vorágine).

El Libro de miseria d'omne se encuentra en un manuscrito único del siglo XV (Santander, Biblioteca Menéndez Pelayo, ms. 77).

Los Gozos de la Virgen están en dos manuscritos: Santander, Biblioteca Menéndez Pelayo, M/77 (con Libro de miseria d'omne) y en Real Academia de la Historia, 9/5809.

Los Proverbios morales de Santob tienen una rica tradición textual, pues se conservan en cinco manuscritos:

Cambridge University, Add. 3.355 (códice facticio del siglo xv, en el que se encuentran también unas Coplas de Yúçuf aljamiadas en hebreo).

Archivo diocesano de Cuenca, legajo 6, n. ${ }^{\circ} 125$ (forman parte de la documentación de un proceso inquisitorial de 1496; el acusado, Ferrán Verde las escribió de memoria).

Escorial, b.IV.21 (ms. del siglo $\mathrm{xV}$ en el que se recogen otros textos moralizantes y didácticos).

Biblioteca Nacional de Madrid, ms. 9216 (también del siglo XV, con otros textos didáctico-moralizantes).

Biblioteca Rodríguez-Moñino, V-6-73 (formaba parte del Cancionero de Barrantes, hoy dispersado o perdido).

Hay además una copia del siglo XIX en la Real Academia Española, 12.

Ediciones: F. Gómez Redondo, Poesía española. 1. Edad Media, Barcelona, Crítica, 1996. «Dio alto que los çielos sostiene», ed. de M. ${ }^{a}$ C. Pescador del Hoyo, NRFH, 14, 1960, págs. 242-250. R. Surtz, «Fragmentos de un Catón glosado en cuaderna vía», JHPh, 6, 1982, págs. 103-112. Beneficiado de Úbeda, Vida de San Ildefonso, ed. M. Alvar Ezquerra, Bogotá, Instituto Caro y Cuervo, 1975. Libro de miseria de omne, ed. P. Tesauro, Pisa, Giardini, 1983. J. Connolly, Translation and Poetization in the Quaderna Via. Studi and Edition of the "Libro de miseria d'omne», Madison, 
HSMS, 1987. Santob de Carrión, Proverbios Morales, de S. Shepard, Madrid, Castalia, 1985. Santob de Carrión, Proverbios Morales, ed. T. A. Perry, Madison, HSMS, 1986. I. González Llubera, Santob de Carrión, «Proverbios morales», Cambridge, University Press, 1947.

Bibliografia: M. Alvar Ezquerra, Concordancias e índices léxicos de la «Vida de San Ildefonso», Málaga, Universidad, 1980. L. Romero Tobar, «La Vida de San Ildefonso del Beneficiado de Úbeda: dos versiones inéditas», RFE, 60, 1978-80, págs. 285-315.

M. Artigas, «Unos gozos de la Virgen del siglo XIV», en Homenaje a Menéndez Pidal, vol. 1, Madrid, 1925, págs. 371-375. A. Gómez Moreno, «Los Gozos de la Virgen en el ms. 9/5809 de la Real Academia de la Historia», in Studia in honorem Prof. M. de Riquer, vol. 4, Barcelona, Quaderns Crema, 1991, págs. 233-245.

A. Gómez Moreno, «Nuevas reliquias de la cuaderna vía», RLM, 2, 1990, págs. 9-34.

T. A. Perry, «The Present State of Shem Tov Studies», C, 7, 1978-9, págs. 3438. L. López Grigera, «Un nuevo códice de los Proverbios morales de Sem Tob», $B R A E, 56,1976$, págs. 221-281.

\section{El Libro de Buen Amor}

Se conservan del Libro de Buen Amor tres códices principales y varios fragmentos o citas de diversa amplitud. Los tres manuscritos más importantes son:

Salamanca, Bibl. Universitaria ms. 2663 (original de 1343; copiado h. 1415; se conoce con la sigla S).

Real Academia Española, Madrid, ms. 19 (copiado en 1389; sigla G). Biblioteca Nacional de Madrid, Vitr. 6-1 (original de 1330; ms. de principios del siglo Xv; sigla T).

Las citas del Arcipreste de Talavera, Lope García de Salazar (Real Academia de la Historia, 9-10-2/2100), un «juglar cazurro» (Salamanca, Universidad, ms. 2497) y algunos otros testimonios del siglo xV (Biblioteca Nacional de Madrid, ms. 9589; Biblioteca Nacional de Madrid, ms. 7896; Salamanca, 2497), y las citas de Alvar Gómez de Castro y Gonzalo Argote de Molina en el siglo XVI (Bibl. de Palacio, Madrid, ms. 880) atestiguan la popularidad alcanzada por la obra, que sin embargo no llegó a ser impresa hasta 1790 (por Tomás Antonio Sánchez, que publica el manuscrito de Salamanca). Hay un fragmento con la versión al portugués, de finales del siglo XIV.

El códice de Salamanca pertenece a una rama de la tradición, mientras que los dos mss. de Madrid derivan de un subarquetipo común. El frag- 
mento portugués, el ms. 9589 y las citas del siglo XVI entroncan con la rama G (Real Academia Española); el resto de los testimonios no pueden adscribirse a ninguna rama en concreto.

Ediciones facsímiles: Juan Ruiz, Libro de buen amor, [ms. G], Madrid, Real Academia Española, 1974. Libro de buen amor, [ms. S], Madrid, Edilán, 1975. Libro de buen amor, [ms. T], en la edic. de M. Criado de Val y E. W. Naylor, Madrid, C.S.I.C., 1978.

Ediciones críticas: Libro de buen amor, ed. G. Chiarini, Milano-Napoli, Riccardo Ricciardi, 1964. Libro de buen amor, ed. J. Corominas, Madrid, Gredos, 1967. Libro de buen amor, ed. G. B. Gybbon-Monypenny, Madrid, Castalia, 1988. Libro de buen amor, ed. F. Sevilla y P. Jauralde, Barcelona, PPU, 1988. Libro de buen amor, ed. A. N. Zahareas, con la colab. de T. McCallum, Madison, HSMS, 1989. J. Joset, Madrid, Taurus, 1990. A. Blecua, Madrid, Cátedra, 1992.

Bibliografia: E. W. Naylor, G. B. Gybbon-Monypenny y A. D. Deyermond, «Bibliography of the Libro de Buen Amor since 1973», C, 7, 1979, págs. 123-135. M. A. Vetterling, A Computerized Bibliography for Juan Ruiz's Libro de Buen Amor, Cambridge (Mass.), desde 1980. J. Jurado, Bibliografia sobre Juan Ruiz y su Libro de Buen Amor, Madrid, C. S. I. C., 1993.

\section{Don Juan Manuel}

Don Juan Manuel depositó un ejemplar de su obra en el monasterio de los frailes predicadores en Peñafiel - según afirma el autor en el prólogo general a sus obras-, pero un incendio acabó con este original. Toda la obra de don Juan Manuel se conserva en un único códice, a excepción de la Crónica abreviada: Biblioteca Nacional de Madrid, ms. 6376 (fin. siglo XIV).

La Crónica abreviada se encuentra en un manuscrito único: Biblioteca Nacional de Madrid, ms. 1356.

El Conde Lucanor se recoge, además, en cuatro manuscritos y un impreso temprano: Real Academia Española, Madrid, ms. 15 (principios del siglo XV); Real Academia de la Historia, Madrid, ms. 9/5893/E-78; Biblioteca Nacional de Madrid, ms. 4236 (ambos de mediados del siglo XV); Biblioteca Nacional de Madrid, ms. 18415 (mediados del siglo XVI); fue impreso por primera vez en Sevilla, en los talleres de Hernando Díaz, el año 1575, gracias a los cuidados de Gonzalo Argote de Molina.

La tradición textual de El Conde Lucanor es compleja: el ms. 6376 de la Biblioteca Nacional de Madrid y el de la Real Academia Española pare- 
cen derivar de un mismo original, con o sin intermediarios; de un subarquetipo diferente derivan la copia de la Real Academia de la Historia y el ms. 4236; por último, el ms. 18415 y el impreso proceden de otro subarquetipo, posiblemente del siglo XVI, que corregía, con el concurso de otras copias no conservadas, un texto del siglo XIV.

Ediciones: J. M. Blecua, Juan Manuel, Obras Completas, 2 vols., Madrid, Gredos, 1982. R. Ayerbe-Chaux, Textos y concordancias de la Obra Completa de Juan Manuel, Madison, HSMS, 1986. Don Juan Manuel, Cinco Tratados: Libro del cavallero et del escudero. Libro de las tres razones. Libro enfenido. Tractado de la asunçion de la Virgen. Libro de la caça, edic. R. Ayerbe-Chaux, Madison, HSMS, 1989.

Bibliografia: D. Devoto, Introducción al estudio de don Juan Manuel y en particular de El Conde Lucanor: una bibliografia, Madrid, Castalia, 1972. Id., «La introducción al estudio de don Juan Manuel diez años después», en Don Juan Manuel. VII Centenario, Murcia, 1982, págs. 63-73. M. ${ }^{a}$ J. Lacarra y F. Gómez Redondo, «Bibliografía sobre don Juan Manuel», Boletín Bibliográfico de la AHLM, 5, 1991, págs. $179-212$.

\section{ABREVIATURAS UTILIZADAS}

AHLM = Asociación Hispánica de Literatura Medieval

BHS = Bulletin of Hispanic Studies

$\mathrm{BNM}=$ Biblioteca Nacional de Madrid

BRAE = Boletín de la Real Academia Española

$\mathrm{C}=\mathrm{La}$ Corónica

$\mathrm{CSIC}=$ Consejo Superior de Investigaciones Científicas
HSMS = Hispanic Seminary of Medieval Studies

$\mathrm{JHPh}=$ Journal of Hispanic Philology NRFH = Nueva Revista de Filología Hispánica

RFE = Revista de Filología Española

RLM = Revista de Literatura Medieval $\mathrm{RPh}=$ Romance Philology 


\section{ÍNDICE DE AUTORES O DE OBRAS}

Alfonso $\mathrm{X}, 5$

Arcipreste de Hita, Libro de Buen Amor, 8

Ay, Iherusalem, 2.5

Baladro del sabio Merlín, 6.2

Barlaam e Josafat, 4.2.14

Bocados de oro, 4.2 .2

Bonium, 4.2.2

Calila e Dimna, 4.2.12

Castigos e documentos del rey don Sancho, 4.2.10

Catón glosado, 7.1

Debate del alma y el cuerpo, 2.1 Demanda del sancto Grial, 6.2

Dichos de sabios, 4.2.3

Dichos del ynfante Epitus, 4.2.7

Diez Mandamientos, 7.1

Dio alto, 7.1

Elena y Maria, 2.3

Estoria de Merlín, 6.2

Fazienda de Ultramar, 4.3

Flores de Filosofia, 4.2.4

Gonzalo de Berceo, 3.1

Gozos de la Virgen, 7.1

Gran Conquista de Ultramar, 6.3

Historia troyana, 6.1

Historia troyana en prosa y verso, 6.1

Juan Manuel, 9

Leyenda de Troya, 6.1

Libro de Alexandre, 3.2

Libro de Apolonio, 3.3
Libro de José de Arimatea, 6.2

Libro de la infancia y muerte de Jesús, 2.4 .2

Libro de Lançarote del Lago, 6.2

Libro de los buenos proverbios, 4.2.1

Libro de los cien capitulos, 4.2.3

Libro de los doze sabios, 4.2.9

Libro de los engaños de las mugeres, 4.2 .13

Libro de miseria d'omne, 7.1

Libro del Cavallero Zifar, 6.4

Libro del consejo e de los consejeros, 4.2.11

Lucidario, 4.4

Mocedades de Rodrigo, 1.2

Poema de Fernán González, 3.4

Poema de mio Cid, 1.1

Poridat de las poridades, 4.2 .8

Razón de amor con los denuestos del agua y el vino, 2.2

Representación de los Reyes Magos, 2.6

Roncesvalles, 1.3

Santob de Carrión, Proverbios morales, 7.2

Segundo y Adriano, 4.2.5

Sendebar, 4.2.13

Teodor la donzella, 4.2.6

Textos menores de la cuaderna vía, 7.1

Traducciones de materia artúrica, 6.2

Tratado de la nobleza y lealtad, 4.2.9

Tratado del ynfante Phiteus, 4.2.7

Tristán de Leonis, 6.2

Vida de S, Ildefonso, 7.1

Vida de Santa María Egipcíaca, 2.4.1 


\section{RELACIÓN DE MANUSCRITOS CITADOS}

Archivo Histórico Nacional, Diversos, miscelánea, caj., 12.2.5, 7.1

Archivo Histórico Nacional, Clero, carp. 279, n. $22,2.1$

Burgos, Seminario de S. Jerónimo, 4.2.10

Cambridge University, Add. 3.355, 7.1

Cuenca, Archivo diocesano, legajo 6, n. $^{\circ} 125,7.1$

Escorial, \&.II.8, 4.2.4; 4.2.9

Escorial, a.IV.9, 4.2.2

Escorial, b.I.2, 5

Escorial, b.IV.21, 3.4; 7.1

Escorial, e.III.10, 4.2.2

Escorial, h.Y.6, 6.1

Escorial, h.I.15, 5

Escorial, h.I.16, 5

Escorial, h.III.1, 4.2.1; 4.2.4; 4.2.8

Escorial, h.III.6, 4.2.2; 4.2.6

Escorial, h.III.9, 4.2.12

Escorial, h.III.24, 4.2.2

Escorial, K.III.4, 2.4; 3.3

Escorial, L.II.16, 6.1

Escorial, L.III.2, 4.2.1; 4.2.8

Escorial, P.III.2, 5

Escorial, S.II.13, 4.2.4

Escorial, T.I.I, 5

Escorial, T.I.6, 5

Escorial, X.I.4, 5

Escorial, X.II.12, 4.2.4

Escorial, X.III.4, 4.2.12

Escorial, Y.I.2, 5

Escorial, Z.III.13, 5

Escorial, Z.III.4, 4.2.10; 4.2.11

Estrasburgo, Bibl. Univ., 1829, 4.2.14

Florencia, Biblioteca Nazionale, B.R. 20,5

Lisboa, Biblioteca Nacional, ms. iluminado n. ${ }^{\circ} 46,4.2 .8$

Londres, British Library, Add. 20787, 5
Londres, British Library, Egerton 939, 4.2.7

Madrid, Biblioteca Rodríguez-Moñino, V-6-73, 7.1

Madrid, Biblioteca Bartolomé March, 20/4/1, 4.2.2

Madrid, Biblioteca de la Universidad Complutense, ms.156, 5

Madrid, Biblioteca de los Duques de Alba, 2.3

Madrid, Biblioteca de Palacio, 168, 4.4

Madrid, Biblioteca de Palacio, 793, 4.4

Madrid, Biblioteca de Palacio, 880, 8

Madrid, Biblioteca de Palacio, II. 569, 4.2.4

Madrid, Biblioteca Nacional, 819, 5

Madrid, Biblioteca Nacional, 1187, 6.3

Madrid, Biblioteca Nacional, 1356, 9

Madrid, Biblioteca Nacional, 1533, 3.1

Madrid, Biblioteca Nacional, 1634, 6.2

Madrid, Biblioteca Nacional, 1920, 6.3

Madrid, Biblioteca Nacional, 2454, 6.3

Madrid, Biblioteca Nacional, 3065, 5

Madrid, Biblioteca Nacional, 3369, 4.4

Madrid, Biblioteca Nacional, 3995, 4.2 .10

Madrid, Biblioteca Nacional, 4202, 7.1

Madrid, Biblioteca Nacional, 4236, 9

Madrid, Biblioteca Nacional, 5548, 7.1

Madrid, Biblioteca Nacional, 6376, 9

Madrid, Biblioteca Nacional, 6545, 4.2.2; 4.2 .8

Madrid, Biblioteca Nacional, 6559, 4.2.10; 4.2.11

Madrid, Biblioteca Nacional, 6603, 4.2.10

Madrid, Biblioteca Nacional, 6608, $4.2 .11 ; 4.2 .3$

Madrid, Biblioteca Nacional, 6936, 4.2.2

Madrid, Biblioteca Nacional, 6958, 4.4

Madrid, Biblioteca Nacional, 7896, 8 
Madrid, Biblioteca Nacional, 8405 , 4.2.2; 4.2.3

Madrid, Biblioteca Nacional, 9055, 4.2.6

Madrid, Biblioteca Nacional, 9204, 4.2.2

Madrid, Biblioteca Nacional, 9216, 4.2.3; 4.2.11; 7.1

Madrid, Biblioteca Nacional, 9248, 4.2.1

Madrid, Biblioteca Nacional, 9266, 4.2.4

Madrid, Biblioteca Nacional, 9294, 5

Madrid, Biblioteca Nacional, 9428, 4.2.4

Madrid, Biblioteca Nacional, 9589, 8

Madrid, Biblioteca Nacional, 9611, 6.2

Madrid, Biblioteca Nacional, 10011, 4.2.7

Madrid, Biblioteca Nacional, 10069, 5

Madrid, Biblioteca Nacional, 10146, 6.1

Madrid, Biblioteca Nacional, 11309, 6.4

Madrid, Biblioteca Nacional, 12733, 4.2.9

Madrid, Biblioteca Nacional, 13149, 3.1

Madrid, Biblioteca Nacional, 17657, 4.2.7

Madrid, Biblioteca Nacional, 17822, 4.2.2; 4.2.6

Madrid, Biblioteca Nacional, 17853, 4.2.2; 4.2.6

Madrid, Biblioteca Nacional, 18017, 4.2.14

Madrid, Biblioteca Nacional, 18415, 9

Madrid, Biblioteca Nacional, 19161, 7.1

Madrid, Biblioteca Nacional, 20262, 6.2

Madrid, Biblioteca Nacional, 22021, 6.2

Madrid, Biblioteca Nacional, Vitr. 5-9, 2.6

Madrid, Biblioteca Nacional, Vitr. 5-10, 3.2

Madrid, Biblioteca Nacional, Vitr. 6-1, 8
Madrid, Biblioteca Nacional, Vitr. 7-17, $1.1 ; 4.2 .7$

Madrid, Fundación Lázaro Galdiano, 419, 7.1

Monasterio de Silos (Congregación S. Benito de Valladolid, t. 36), 3.1

Monasterio de Silos, ms. 12, 3.1

Monasterio de Silos, ms. 93, 3.1

New York, Hispanic Society, 4.2.4

Oviedo, Biblioteca de la Catedral, 4.2 .12

Pamplona, Archivo Provincial, 1.3 París, Bibliothèque de l'Arsenal, ms. 8322, 5

París, Bibliothèque Nationale, Esp. 12, 1.2

París, Bibliothèque Nationale, Esp. 36, 6.4

París, Bibliothèque Nationale, Esp. $488,3.2$

París, Bibliothèque Nationale, lat. 3576, 2.2

Real Academia de la Historia 9-5809, 7.1

Real Academia de la Historia, 101, 4.4

Real Academia de la Historia, 12-4-1, 3.1

Real Academia de la Historia, 9-10$2 / 2100,6.2$

Real Academia de la Historia, 95893/E-78, 9

Real Academia Española (mss. 4 y 4b), 3.1

Real Academia Española, 12, 7.1

Real Academia Española, 15, 4.2.13; 4.4; 9

Real Academia Española, 19, 8

Ripoll, Biblioteca Lambert Mata, 4.2.2

Salamanca, Biblioteca Universitaria, $1698,6.3$

Salamanca, Biblioteca Universitaria, $1763,4.2 .1 ; 4.2 .2 ; 4.2 .3 ; 4.2 .12$ 
Salamanca, Biblioteca Universitaria, $1866,4.2 .2 ; 4.2 .6$

Salamanca, Biblioteca Universitaria, $1877,4.2 .14 ; 6.2$

Salamanca, Biblioteca Universitaria, 1958, 4.4

Salamanca, Biblioteca Universitaria, 1997, 4.3

Salamanca, Biblioteca Universitaria, 2497, 8

Salamanca, Biblioteca Universitaria, 2663, 8

Santander, Biblioteca Menéndez Pelayo, 53, 4.2.2

Santander, Biblioteca Menéndez Pelayo, $77,4.2 .9 ; 7.1$
Santander, Biblioteca Menéndez Pelayo, $558,6.1$

Santander, Biblioteca Menéndez Pelayo, $\mathrm{M} / 108,4.2 .3$

Santiago de Compostela, Biblioteca Universitaria, 4.2.2

Santo Domingo de la Calzada, Biblioteca Manrique de Lara, 3.1

Sevilla, Archivo Ducal de Medinaceli (archivo histórico, 37-50), 3.2

Sigüenza, Seminario Conciliar, 4.2.10

Vaticano 6428, 6.2

Vaticano, Reg. Lat. 1283, 5

Vaticano, Urb. Lat. 539, 5 